\title{
Zeitgeist or chameleon? A quantitative analysis of CSR definitions
}

\author{
Soumodip Sarkar ${ }^{\mathrm{a}, \mathrm{b},{ }^{*}, \text {, Cory Searcy }}{ }^{\mathrm{c}}$ \\ ${ }^{a}$ CEFAGE-UE and Department of Management, University of Évora, Palácio do Vimioso (Gab. 224), Largo Marquês de Marialva, 8, $7000-809$ Évora, Portugal \\ ${ }^{\mathrm{b}}$ Asia Center, Harvard University, Cambridge, MA 02138, USA \\ ${ }^{\mathrm{c}}$ Ryerson University, Toronto, ON M5B 2K3, Canada
}

\section{A R T I C L E I N F O}

\section{Article history:}

Received 7 February 2016

Received in revised form

3 May 2016

Accepted 25 June 2016

Available online 9 July 2016

\section{Keywords:}

Corporate social responsibility

Definitions

Social network analysis

Co-word analysis

Review

\begin{abstract}
A B S T R A C T
Despite its increasing relevance, corporate social responsibility (CSR) remains hobbled by problems, variously charged as being chameleon, vacuous or an utterly meaningless concept. One reason is the absence of an agreed upon normative basis underpinning CSR. This is in large part due to the concept lacking a universally accepted definition. This paper explores how the concept of CSR has evolved over time drawing from 110 definitions of the construct. Using co-word analysis of definitions from 1953 to 2014, the study maps how the structure of the definitions has evolved during the field's historical development. The research uncovers the key terms underpinning the phenomenon, the centrality of these terms as well as mapping their interrelationships and evolution. The findings suggest that, despite the profusion and definitional heterogeneity over the six decades of the development of the field, there are six recurrent, enduring dimensions that underpin the CSR concept. These dimensions are economic, social, ethical, stakeholders, sustainability and voluntary. This paper makes several contributions to the academic literature. The systematic, quantitative analysis of definitions brings an objectivity that previous qualitative bibliometric analyses of CSR have lacked. The time period selected is substantially longer than previous analyses and captures the complete historical evolution of the concept. Moreover, the analysis provides the basis for the development of a new, comprehensive, yet concise, definition of CSR that captures all six of the recurring dimensions underpinning the concept.
\end{abstract}

(c) 2016 Elsevier Ltd. All rights reserved.

\section{Introduction}

Since the 1950s, there has been a "great acceleration" in the human imprint on the natural world (Steffen et al., 2015). There have been dramatic shifts in key earth systems trends, such as emissions of greenhouse gases (GHG), and socio-economic trends, such as urban population growth (Steffen et al., 2015). These changes have helped drive increased attention on global sustainable development.

Commonly defined as "meeting the needs of the present generation without compromising the ability of future generations to meet their own needs" (WCED, 1987), sustainable development is a broad concept that addresses economic, environmental, and social issues. In recognition of the need to take concrete action on sustainable development, the United Nations recently adopted 17

\footnotetext{
* Corresponding author. CEFAGE, University of Évora, Palácio do Vimioso (Gab. 224), Largo Marquês de Marialva, 8, 7000-809 Évora, Portugal.

E-mail addresses: ssarkar@uevora.pt (S. Sarkar), cory.searcy@ryerson.ca (C. Searcy).
}

Sustainable Development Goals (SDGs). However, given its broad scope, it is clear that sustainable development cannot be addressed by the public sector alone.

Private sector contributions to sustainable development are essential (SDG Compass, 2015). Many corporations have committed to working towards sustainable development and a number of industry associations, such as the World Business Council for Sustainable Development (WBCSD), have been established to coordinate action in this regard. As a tangible manifestation of these commitments, many corporations have voluntarily implemented corporate social responsibility (CSR) programs. CSR is now viewed by many as the key corporate contribution to sustainable development (Kolk and Van Tulder, 2010). In fact, the world's most widely recognized social responsibility standard explains that "an overarching objective of an organization's social responsibility should be to contribute to sustainable development" (ISO 26000, 2010, p. 9).

CSR has become a modern corporate mantra. A range of internal and external stakeholders now widely encourage firms to behave responsibly in a variety of respects, such as the use of resources, 